\title{
Production of Biomethane from Cafeteria, Vegetable and Fruit Wastes by Anaerobic Co-Digestion Process
}

\author{
Muhammad Rashed Al Mamun and Shuichi Torii
}

\begin{abstract}
Alleviate energy crisis and global climate change, the world is need of a green, efficient, carbon-neutral renewable energy source to replace fossil fuels. This study was designed to determine the optimal mixing ratio of cafeteria, vegetable and fruit wastes in biogas production and methane yields using batch anaerobic digesters at mesophilic $\left(25\right.$ to $\left.34^{\circ} \mathrm{C}\right)$ temperature. The mixing ratio used were $\mathrm{CW}: \mathrm{VW}: \mathrm{FW}$ (0.5:1.0:1.5, 1.0:1.5:0.5, 1.5:0.5:1.0 and 1.0:1.0:1.0) for cafeteria waste $(\mathrm{CW})$, vegetable waste $(\mathrm{VW})$ and fruit waste $(\mathrm{FW})$ respectively. The fermentation was carried out in $200 \mathrm{~L}$ polypropylene digesters. The results showed that the codigestion significantly affected the biogas production rate. At four mixing ratio tested, after 35 days of digestion, the biogas yield was determined to be CW:VW:FW (0.5:1.0:1.5, 1.0:1.5:0.5, 1.5:0.5:1.0 and 1.0:1.0:1.0) were 13.38, 15.85, 17.03 and $19.43 \mathrm{~L} / \mathrm{day}$, respectively. The cumulative average biogas productions from CW:VW:FW (0.5:1.0:1.5, 1.0:1.5:0.5, 1.5:0.5:1.0 and 1.0:1.0:1.0) were $225,279,305$ and $332 \mathrm{~L} / \mathrm{day}$, respectively. The biogas yields obtained in the work for the cafeteria $(\mathrm{CW})$, vegetable $(\mathrm{VW})$ and fruit wastes $(\mathrm{FW})$ mixture were in the order of $(1.0: 1.0: 1.0>1.5: 0.5: 1.0>1.0: 1.5: 0.5>$ $0.5: 1.0: 1.5)$. The higher methane contents and yields were obtained from the CW:VW:FW (1.0:1.0:1.0) mixture ratio than those from the CW:VW:FW (1.5:0.5:1.0, 1.0:1.5:0.5, and $0.5: 1.0: 1.5)$. Thus, optimum mixing ratio suggested by the study which gave maximum yields within 35 day hydraulic retention time without inoculums added.
\end{abstract}

Index Terms-Anaerobic digestion, biogas, renewable energy, cafeteria waste $(\mathrm{CW})$, vegetable waste $(\mathrm{VW})$, fruit waste $(\mathbf{F W})$.

\section{INTRODUCTION}

In the present scenario both energy crisis and change in climate are key issues all over the world. There will be severe scarcity of energy in the next few decades. Worldwide energy crisis directed the attention to the alternative sources of energy instead of underground fossil fuel. The use of fossil fuels as primary energy source has lead to global climate change, environmental degradation and human health problems [1]. Global climate change will inevitably lead to drought, flooding, increases in hurricanes and tornadoes and possibly widespread crop failures and global warming [2], [3]. Despite rapid globalization, Bangladesh, like other third world agro based countries. Among the total annual harvest a significant portion of land is devoted for vegetable cultivation across the country. But, because of the deficiency of efficient transportation and

Manscript received May 18, 2014; revised August 20, 2014.

The authors are with Department of advanced Mechanical System Engineering, Graduate school of Science and Technology, Kumamoto University, 2-39-1 Kurokami, Kumamoto 860-8555 Japan (e-mail: rashedshahi@gmail.com; torii@mech.kumamoto-u.ac.jp). preservation a huge amount of those vegetables are wasted firstly in the land where it was grown and then in the vegetable market as municipal waste. Due to their high moisture and organic contents and biodegradability, the food and green wastes are major contributors to the emissions of greenhouse gases and volatile organic compounds. From the standpoint of pollution control, green and food wastes are not hazardous materials but their disposal in landfill poses serious environmental problems [4]. Therefore, security of energy supply, especially development of sustainable energy and reduction of $\mathrm{CO}_{2}$ emission are priorities on agenda worldwide. In this regard, biogas is a renewable energy resources appear to be one of the most efficient and effective solutions [5]. It is carbon neutral colorless, flammable gas produced from animal, plant, human, industrial and municipal wastes amongst others, to give mainly methane (50-70\%), carbon dioxide (20-40\%) and traces of other gases such as nitrogen, hydrogen, ammonia, hydrogen sulphide, water vapour etc. [6].

Kumamoto University (KU) is one of the most reputed educational institutions in Japan, which plays vital role in producing more number of Science and Engineering graduates. Graduate School of Science and Technology, (KU) cafeteria produced wastes are getting accumulated everyday and these wastes can be effectively used for biogas generation as well as bio-fertilizer production. Cafeteria wastes contain cooked-food wastes, cooked-vegetable wastes etc. Vegetable and fruit wastes are also plentiful in nearby the vegetable market. Therefore, experiments have concentrated to produce biogas with the mixtures of cafeteria, Vegetable, and fruit wastes by anaerobic digestion. Anaerobic digestion is a process in which organic substrates are degraded in the absence of oxygen, via enzymatic and bacterial activities producing biogas that could be used as a renewable energy source. Many digester designs are being applied for different wastes and wastewaters. Batch digesters are simple both in construction and operation. These digesters are applied in large scale installations and in laboratories when assessing the biochemical methane potential (BMP). In a normal start-up of a batch digester, a certain amount of inoculum should be added together with the substrate to provide the required microorganisms to start reactions. Then digesters are incubated at mesophilic (25$35^{\circ} \mathrm{C}$ ) or thermophilic $\left(45-60^{\circ} \mathrm{C}\right)$ conditions for a certain period of time. According to Bouallagui et al. (2005), fruit and vegetable wastes are high biodegradable substrates; about $70-95 \%$ of the organic matter could be converted into biogas [7]. Guanaseelan (2004) determined the BMP of 54 fruits and vegetable wastes [8]. The ultimate methane yields of fruit feedstocks ranged from 180 to $730 \mathrm{~mL} / \mathrm{g}$ VS added and that of vegetable wastes ranged from 190 to $400 \mathrm{~mL} / \mathrm{g}$ 
VS added. The methane yield depended not only on the fruit and vegetable variety but also on the different fruit parts within the same variety. The stable gas production is obtained in anaerobic co-digestion of wasted tomatoes and cattle dung for biogas production [9]. They had shown that a conversion of $72.5 \%$ of the organic solids fed into the digester at 20 days hydraulic retention days was obtained. The average gas yield was $220 \mathrm{dm}^{3} / \mathrm{Kg}$ VS added. They used $7 \%$ total initial solids and later diluted to $3.5 \%$ to avoid clogging.

Numerous studies, researches, and implementation of findings have been going on globally to produce biogas from food wastes. Biswas et al., conducted a comprehensive study on biogas kinetics and they used the municipal wastes as the source of biogas [10]. They used a $10 \mathrm{dm}^{3}$ anaerobic batch digester equipped with a mechanical agitator under controlled environment at $\mathrm{pH} 6.8$ and temperature $40{ }^{\circ} \mathrm{C}$ for that purpose. Cho et al. conducted batch digestion tests of food wastes at $37^{\circ} \mathrm{C}$ and 28 days retention time [11]. The methane yields were $0.48,0.29,0.28$, and $0.47 \mathrm{~L} / \mathrm{g}$ VS for cooked meat, boiled rice, fresh cabbage and mixed food wastes, respectively. Heo et al., evaluated the biodegradability of a traditional Korean food waste consisting of boiled rice $(10 \%-15 \%)$, vegetables $(65 \%-$ $70 \%)$, and meat and eggs $(15 \%-20 \%)$ and showed a methane yield of $0.49 \mathrm{~L} / \mathrm{g} \mathrm{VS}$ at $35^{\circ} \mathrm{C}$ after 40 days retention time [12]. Zhang et al., analyzed the nutrient content of food waste from a restaurant, showing that the food waste contained appropriate nutrients for anaerobic microorganisms, as well as reported a methane yield of 0.44 L/g VS of food waste in batch digestion test under thermophilic conditions $\left(50^{\circ} \mathrm{C}\right)$ after 28 days [13]. Anaerobic digestion of food waste is achievable; however different types of food waste result in varying degrees of methane yields, and thus the effects of mixing various types of solid organic wastes and their proportions should be determined on a case by case basis. The objective of this study was to find the optimum conditions and mixing ratios for improved production of biogas using co-digestion with the help of cafeteria, vegetables, and fruits wastes under mesophilic conditions in batch mode digester. The digestibility was evaluated in terms of biogas and methane production yield from the mixture of cafeteria, vegetables, and fruits wastes under different conditions of $\mathrm{P}^{\mathrm{H}}$, temperature, and digestion time. This paper has been focused and monitored the optimum conditions for the biogas production without inoculum added.

\section{MATERIALS AND METHOD}

\section{A. Collection of Fermentation Slurries}

The vegetable and fruit waste were collected from Kokai vegetable market, Kumamoto, Japan. Cafeteria waste was collected from the cafeteria of Kumamoto University. The materials was stored at $4^{\circ} \mathrm{C}$ and used for the experiment.

\section{B. Fermentation Slurries Preparation}

$75 \mathrm{~kg}$ of cafeteria, vegetable and fruit wastes were weighed and mixed in the ratio of CW:VW:FW 0.5:1.0:1.5, 1.0:1.5:0.5, 1.5:0.5:1.0 and 1.0:1.0:1.0, were diluted with tap water at 1:1 ratio, mixed properly to obtain homogenous conditions. According to the mentioned ratio the prepared material fed in $200 \mathrm{~L}$ batch type digesters for a period of 35 days to determine the effect of mixture ratio. In order to optimize gas production, feed stock was maintained $8 \%$ of TS concentration by mass. All wastes were crushed separately into small particle sizes with the help of mechanical crusher and were adjusted to $8 \%$ by diluting with water. This slurry was filled $80 \%$ of reactor through inlet and leakage was checked. The prevailing temperature range was 25 to $34^{\circ} \mathrm{C}$ during the period of study. The experiment was conducted at suboptimum condition (ambient temperature without any form of temperature regulation, inoculums, $\mathrm{pH}$, pretreatment of substrates etc.). The bio-digester is divided into three main parts- the inlet chamber, the body, and the outlet chamber. An exit $13 \mathrm{~mm}$ diameter hose pipe is provided at the top of the smaller cylindrical portion of the digester for biogas collection and measurement. The digesters used for the experiment was made of polypropylene with an air tight rubber gasket, which is durable and potable for waste management. Other materials used for the experiment include graduated plastic bucket, glass flask and beaker for measuring the volume of gas production, gas pressure gauge, hosepipe, thermometer, digital $\mathrm{p}^{\mathrm{H}}$ meter. Biogas production was monitored and measured for 35 days. The experimental set up used for the research is shown in Fig. 1.

\section{Data Collection and Analysis}

All wastes ratio were analyzed for the following parameters:

1) $\mathrm{pH}$ measurement: $\mathrm{pH}$ measurement was monitored using $\mathrm{pH}$ meter HM-25R (TOADKK). The mean $\mathrm{PH}$ was calculated from the collected $\mathrm{PH}$ results every day.

2) Total solids (TS) and total volatile solids (VS) standard methods: TS were determined at $104^{\circ} \mathrm{C}$ to constant weight and VS were measured by the loss on ignition of the dried sample at $550^{\circ} \mathrm{C}$ [14].

3) Biogas collection: Biogas produced by anaerobic digestion was measured by water displacement method [15] as shown in Fig. 2

4) Biogas composition: The Gas composition was analyzed by using a gas chromatography (GC-8AIT / CR8A SHIMADZU Corporation, JAPAN).

5) Pressure: The pressure was higher than atmospheric level measured by gas pressure gauge.

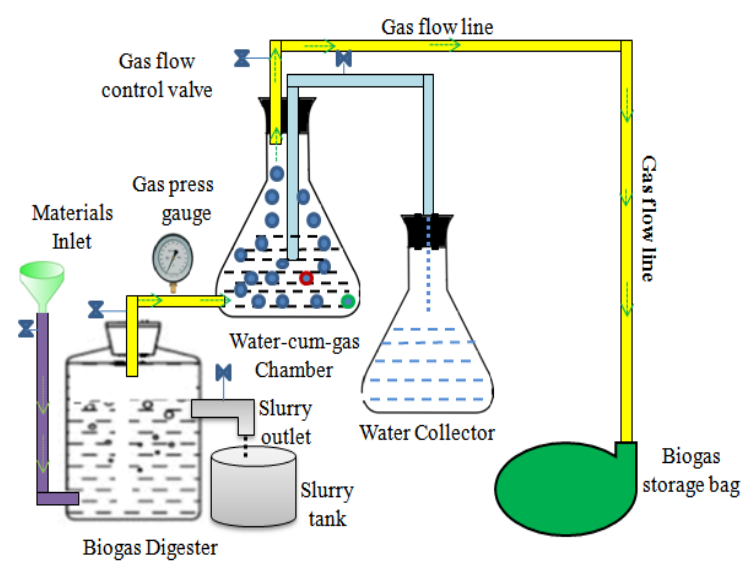

Fig. 1. Schematic for generation of biogas from solid biomass. 


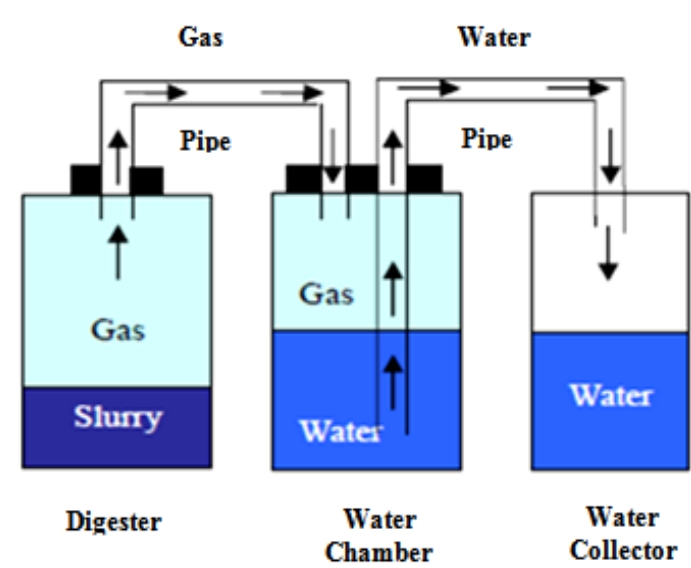

Fig. 2. Schematic of water displacement method.

\section{RESUlTS AND DISCUSSION}

\section{A. Biogas Production Potentials of Mixture}

The biogas yields during the digestion process at mesophilic temperature with different mixing ratio are shown in Fig. 3. Biogas production started immediately from the first day. The higher value of daily biogas production rate was obtained at ratio of $\mathrm{CW}: \mathrm{VW}: \mathrm{FW}$ (1.0:1.0:1.0) in the first day of digestion. The daily biogas production rate was below those of the other three ratios. This optimum condition must be responsible for the quick production of biogas by $\mathrm{CW}: \mathrm{VW}: \mathrm{FW}$ (1.0:1.0:1.0) digester among the various mixtures.

The daily biogas production varies from a minimum of $0.8 \mathrm{~L} /$ day for $\mathrm{CW}: \mathrm{VW}: \mathrm{FW}(0.5: 1.0: 1.5)$ ratio to a maximum of 39 L/day for CW:VW:FW (1.0:1.0:1.0) ratio. From Fig. 3 several peaks were observed for co-digestion of solid biomass. The daily biogas trend of several peaks in this research work could be attributed to the effect of temperature and $\mathrm{P}^{\mathrm{H}}$ fluctuations which are major factor in biogas yield. However, the average daily biogas yield observed from the four mixtures $\mathrm{CW}: \mathrm{VW}: \mathrm{FW}(0.5: 1.0: 1.5$, 1.0:1.5:0.5, 1.5:0.5:1.0 and 1.0:1.0:1.0) were 13.38, 15.85, 17.03 and $19.43 \mathrm{~L} /$ day, respectively.

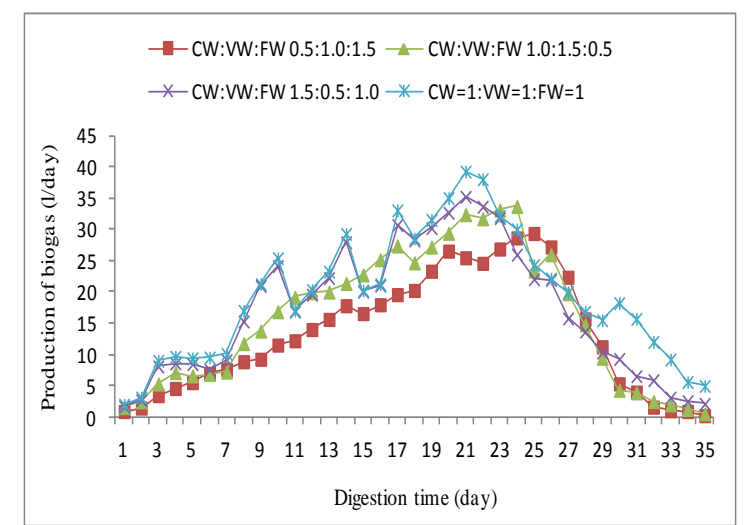

Fig. 3. Daily biogas production rates from of all samples with different mixing ratio.

Biogas production yield seems to be lower at the beginning and at the end of each digestion mixture. The general trend is predicted due to the biogas production rate in batch condition directly corresponds to specific growth rate of methanogenic bacteria in the bio-digester [16]-[18].
The daily biogas yield reached the highest peak value for CW:VW:FW (0.5:1.0:1.5) mixture on $25^{\text {th }}$ day, while the daily biogas yield for $\mathrm{CW}: \mathrm{VW}: \mathrm{FW}$ (1.5:0.5:1.0 and $1.0: 1.0: 1.0)$ reached their peak value on $21^{\text {th }}$ day. On the day $24^{\text {th }}$, the $\mathrm{CW}: \mathrm{VW}: \mathrm{FW}(1.0: 1.5: 0.5)$ mixture reached its peak. Then biogas production declined as compared with the digestion time. The observed least gas yield from these digesters might be due to the production of volatile fatty acids by the microorganism which hinders the releasing of the biogas. This is in agreement with the report of [19] who also observed low level of biogas production due to the lag phase of microbial growth during these periods of the run.

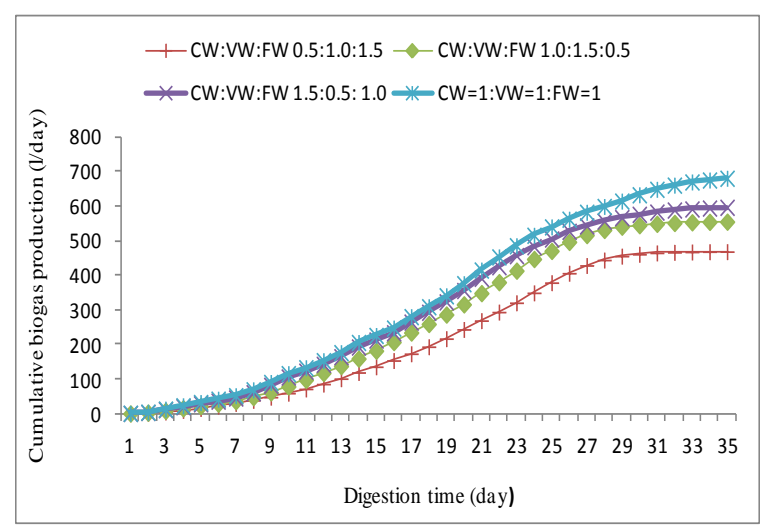

Fig. 4. Cumulative biogas yield of all samples with different mixing ratio

\section{B. Cumulative Study of Results}

The cumulative biogas production tends to obey sigmoid function (S curve) for all digesters are shown in Fig. 4. Within the first few days of observation, biogas production was slightly low. The results shows that at the first 5 days of gas production for the different mixing ratio, the $\mathrm{CW}$ :VW:FW (1.0:1.0:1.0) ratio of digester had the highest biogas yield (15.63 L/day). This might be due to mixing of all substrates at equal mixing ratio provided balanced nutrients, buffering capacity, appropriate $\mathrm{C} / \mathrm{N}$ ratio and sufficient anaerobic microorganisms. However, the final cumulative biogas productions by the co-digestion of cafeteria, vegetable and fruit wastes at different mixing ratios $\mathrm{CW}: \mathrm{VW}: \mathrm{FW}$ (0.5:1.0:1.5, 1.0:1.5:0.5, 1.5:0.5:1.0 and 1.0:1.0:1.0) were 7880, 9768, 10698 and $11637 \mathrm{~L}$, respectively. This means that the cumulative average biogas productions from $\mathrm{CW}: \mathrm{VW}: \mathrm{FW}$ (0.5:1.0:1.5, 1.0:1.5:0.5, 1.5:0.5:1.0 and 1.0:1.0:1.0) were 225, 279, 305 and 332 L/day, respectively. The CW:VW:FW (1.0:1.0:1.0) digester produced the highest total volume of biogas; this is higher than the slurry produced by other mixing ratio. The ratio $\mathrm{CW}$ :VW:FW (0.5:1.0:1.5), digester had the least gas yield of $7880 \mathrm{~L}$; this could be attributed to suboptimum substrate ratio. Biogas yield was significantly influenced by codigestion of the three substrates. The order of gas production is $\mathrm{CW}: \mathrm{VW}: \mathrm{FW}(1.0: 1.0: 1.0>1.5: 0.5: 1.0>1.0: 1.5: 0.5>$ $0.5: 1.0: 1.5)$.

\section{PH and Temperature Pattern during Anaerobic Digestion}

The average pattern of $\mathrm{pH}$ demonstrated by all experimental mixing ratios was typical of a digester operating under stable condition are shown in Fig. 5. A decrease in the process $\mathrm{pH}$ was observed in the first few 
days of the digestion and this is due to high volatile fatty acid (VFA) formation [20]. The initial $\mathrm{P}^{\mathrm{H}}$ was 6.8, an increases fluctuation in $\mathrm{P}^{\mathrm{H}}$ was observed after a sharp drop in the first week of fermentation.

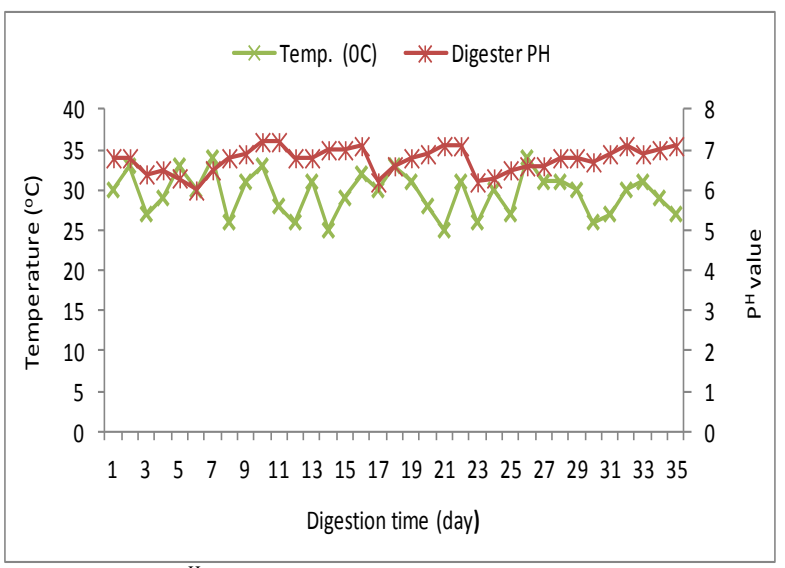

Fig. 5. Daily $\mathrm{P}^{\mathrm{H}}$ and temperature profile during digestion process.

However, the $\mathrm{p}^{\mathrm{H}}$ increased to its normal operating value after VFAs metabolism. The average $\mathrm{P}^{\mathrm{H}}$ of 7.1 was recorded at the end of the experiment. The mean daily records of temperature during the digestion process were investigated. The temperature remained at mesophilic range throughout the study. The lowest temperature reading of $25^{\circ} \mathrm{C}$ was obtained on the fourteen day while the highest of $34^{\circ} \mathrm{C}$ was recorded on the seventh and twenty sixth day of the digestion process. The average temperature of $29.54^{\circ} \mathrm{C}$ was recorded at the end of the 35 day hydraulic retention time (HRT).

\section{Methane Production Rate over the Study Period}

Fig. 6 shows that the methane contents of biogas produced from various biodegradable materials under different mixing conditions. The results presents that the highest methane produced for the mixing ratio of CW:VW:FW $\quad(0.5: 1.0: 1.5, \quad 1.0: 1.5: 0.5, \quad 1.5: 0.5: 1.0$ and $1.0: 1.0: 1.0)$ were $65.23 \%, 72.13 \%, 67.15 \%$, and $73.24 \%$ on the $9^{\text {th }}, 19^{\text {th }}, 16^{\text {th }}$ and $17^{\text {th }}$ day respectively during the digestion process. However, the cafeteria, vegetable and fruit wastes, at mixing ratio of $\mathrm{CW}: \mathrm{VW}: \mathrm{FW}(0.5: 1.0: 1.5$, 1.0:1.5:0.5, 1.5:0.5:1.0 and 1.0:1.0:1.0) under mesophilic conditions, the average methane contents were $59.89 \%$, $60.80 \%, 61.34 \%$, and $63.75 \%$, respectively.

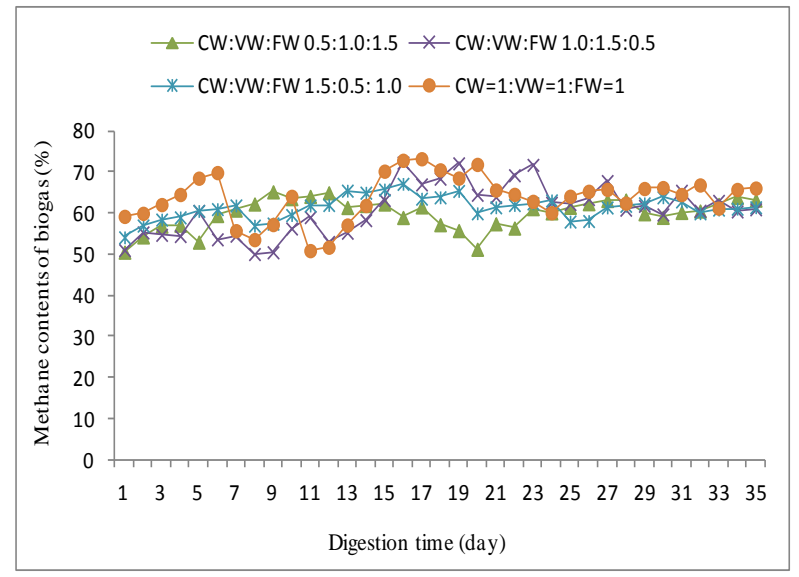

Fig. 6. Methane content of raw biogas from anaerobic co-digestion with different mixing ratio.

\section{E. Discussion}

The results demonstrate that biogas yields after 35 day digestion time are influenced by the mixing ratio: the equal ratio the higher biogas yield. This positive relation might be due to high methanogenic activity and/or the number of methanogens, in the digesters, that could result in the fewer amounts of the volatile fatty acids (VFA) produced during the acidogenic step. Nevertheless, the final average $\mathrm{pH}$ values measured for all studied reactors were at least 7.1. More research is needed to find out the exact reason (s) for the inverse relation between the mixing ratio of cafeteria (food waste) with vegetable and fruit and biogas yield.

The results of this study are not only important for small digesters but also when sizing large scale batch digesters for cafeteria (food waste), vegetable and fruit waste a mixture of them. It is important to point out that without inoculum biogas produced in a significant amount under batch digester is possible. Obviously, the inoculum should be provide more biogas yield when starting a new batch digester but volume should be taken into consideration to provide a specific amount of VS depend on the VS and VSS concentrations in the inoculum.

\section{CONCLUSIONS}

The effects of different mixing ratios on the biogas and methane yield from cafeteria waste $(\mathrm{CW})$, vegetable waste (VW) and fruit waste (FW) were studied using batch anaerobic digester under mesophilic conditions. The results showed a positive relation between biogas yield and mixing in the ratios of $\mathrm{CW}: \mathrm{VW}: \mathrm{FW}(0.5: 1.0: 1.5,1.0: 1.5: 0.5$, 1.5:0.5:1.0 and 1.0:1.0:1.0). The maximum biogas production potential for the biodegradable biomass mixture is in the order of CW:VW:FW (1.0:1.0:1.0 > 1.5:0.5:1.0 > $1.0: 1.5: 0.5>0.5: 1.0: 1.5)$. This shows that the optimum mixture ratio is the $\mathrm{CW}: \mathrm{VW}: \mathrm{FW}(1.0: 1.0: 1.0)$ mixture ratio with $11637 \mathrm{~L}$ within the period under study. On average, higher methane contents biogas were obtained from the CW:VW:FW (1.0:1.0:1.0) mixture ratio than those from the CW:VW:FW (1.5:0.5:1.0, 1.0:1.5:0.5, and 0.5:1.0:1.5). The data obtained from this study could be used as a basis for designing large scale anaerobic digesters for treatment of cafeteria, vegetable and fruit waste and their mixture. Successful digestion of these substrates at suboptimum condition is a means of providing environmental friendly waste management system which will go a long way in providing clean environment, renewable energy.

\section{ACKNOWLEDGEMENT}

The authors acknowledged the extended help of Thermal laboratory under the Department of Advanced Mechanical System Engineering, Kumamoto University, Japan for providing the facility for experimentation.

\section{REFERENCES}

[1] I. N. Budiyano, J. Widiasa, and S. Sunarso, "Increasing biogas production rate from cattle manure using rumen fluid as inoculums," Int. J. Chem and Basic \& Applied Sci., vol. 10, pp. 68-75, 2010.

[2] Z. Sen, "Global warming threat on water resources and environment: a review," Environmental Geology, vol. 57, pp. 321-329, 2009. 
[3] D. M. M. A. Mills, "Climate change, extreme weather events, and us health impacts: what can we say?" J. Occupational and Env. Medicine, vol. 51, no. 1, pp. 26-32, 2009.

[4] P. K. Thassitou and I. S. Arvanitoyannis, "Bioremediation: a novel approach to food waste management," Trends in Food Sci. and Techno, vol. 12, pp. 185-196, 2001.

[5] K. Kaygusuz and A. Kaygusuz, "Renewable energy and sustainable development in Turkey," Renewable Energy, vol. 25, pp. 431-453, 2002.

[6] S. M. Maishanu, M. Musa, and A. S. Sambo, "Biogas technology: The output of the sokoto energy research centre," Nigerian J. of Solar Energy, vol. 9, pp. 183-194, 1990.

[7] H. Bouallagui, Y. Touhami, R. Ben Cheikh, and M. Hamdi, "Bioreactor performance in anaerobic digestion of fruit and vegetable wastes," Process Biochemistry, vol. 40, pp. 989-995, 2005.

[8] V. N. Guanaseelan, "Biochemical methane potential of fruits and vegetable solid waste feedstocks," Biomass and Bioenergy, vol. 26, pp. 389-399, 2004.

[9] M. Saev, B. Koumanova, and I. Simeonov, "Anaerobic co-digestion of wasted tomatoes and cattle dung for biogas production," Journal of the University of Chemical Technology and Metallurgy, vol. 44, no. 1, pp. 55-60, 2009.

[10] J. Biswas, R. Chowdhury, and P. Bhattacharya, "Kinetic studies of biogas generation using municipal waste as feed stock," Enzyme and Microbial Technology, vol. 38, pp. 493-503, 2006.

[11] J. K. Cho, S. C. Park, and H. N. Chang, "Biochemical methane potential and solid state anaerobic digestion of Korean food wastes," Bioresour Technol, vol. 52, no. 3, pp. 245-253,1995.

[12] N. H. Heo, S. C. Park, and H. Kang, "Effects of mixture ratio and hydraulic retention time on single-stage anaerobic co-digestion of food waste and waste activated sludge," $J$ Environ Sci Health A Tox Hazard Subst. Environ Eng., vol. 39, no. 7, pp. 1739-1756, 2004.

[13] R. Zhang, H. M. El-Mashad, K. Hartman, F. Wang, G. Liu, and C. Choate, "Characterization of food waste as feedstock for anaerobic digestion," Bioresour Technol., vol. 98, no. 4, pp. 929-935, 2007.

[14] APHA, Standard Methods for the Examination of Water and Waste Water, 19th ed. Washington DC. pp. 525-987, 1995.

[15] S. L. Ezeoha and F. I. Idike, "Biogas production potential of cattle paunch manure," Journal of Agricultural Engineering and Technology, vol. 15, pp. 25-31, 2007.

[16] A. Gupta, R. Chandra, P. M. V. Subbarao, and V. K. Vijay, "Kinetics of batch biomethanation process of jatropha and pongamia oil cakes and their co-digested subtrates," J. Scient. Ind. Res., vol. 68, pp. 624$629,2009$.

[17] A. B. Rabah, A. S. Baki, L. G. Hassan, M. Musa, and A. D. Ibrahim, "Production of biogas waste at different retention time," Sci. World J., vol. 5, no. 4, pp. 23-26, 2010.

[18] P. L. Luengo and J. M. Alvarez, "Influence of temperature, buffer, composition and straw particle length on the anaerobic digestion of wheat straw-pig manure mixtures," Resources, Conservation and Recycling, vol. 1, no. 1, pp. 27-37, 1988.

[19] I. N. Budiyono, S. Widiasa, Johari, and Sunarso, "Increasing biogas production rate from cattle manure using rumen fluid as inoculums," Int. J. Basic Applied Sci., vol. 10, pp. 41-47, 2010.

[20] M. S. Rao, S. P. Singh, A. K. Singh, and M. S. Sodha, "Bioenergy conversion studies of the organic fraction of MSW: assessment of ultimate bioenergy production potential of municipal garbage," Applied Energy, vol. 66, pp. 75-78, 2000.

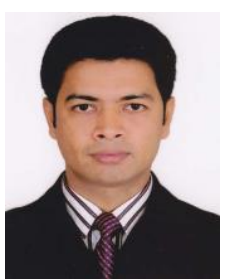

Muhammad Rashed Al Mamun was born on February 8, 1982 in Kaliganj, Dhaka-Gazipur, Bangladesh. Al Mamun successfully completed B.Sc. degree in agricultural engineering and master's degree in farm power and machinery from Bangladesh Agricultural University, Mymensingh, Bangladesh in 2005 and 2007 respectively.

Now he is pursuing $\mathrm{PhD}$ degree under the Department of Advanced Mechanical System Engineering at Kumamoto University, Japan from April 2013.

$\mathrm{He}$ is an assistant professor in the Department of Farm Power and Machinery, Faculty of Agricultural Engineering and Technology in Sylhet Agricultural University, Sylhet, Bangladesh. Prior to this position, he worked as a lecturer for the same University and agricultural engineer at the Department of Agricultural Extension in Ministry of Agriculture, Dhaka, Bangladesh. He was working in the field of renewable energy based on biomass which supplies energy in rural areas and developed of improve utilization technology. His research interests include renewable energy, agricultural machinery, precision agriculture, and GIS based agricultural policy management for sustainable agriculture in rural areas.

Mr. Al Mamun is a member of Engineering Institute of Bangladesh (IEB) and Krishibid Institute of Bangladesh (KIB).

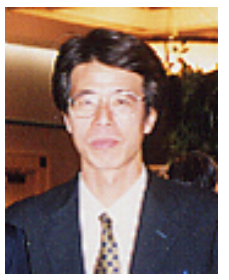

Shuichi Torii was born on January 27, 1960 in kumamoto, Japan.

$\mathrm{He}$ received his B.Sc. degree in mechanical engineering from Kagoshima University, Japan in 1983. He successfully completed his master and $\mathrm{PhD}$ degrees in mechanical engineering from Kyushu University, Japan in 1985 and 1989 respectively.

He worked as a lecturer at Kyushu University, Japan. He also worked as a visiting scholar at University of Michigan, where he studied the solidification and oxidization in reactor using the experimental method and numerical simulation. In 1993, he became an associate professor at Kagoshima University, where he studied the thermal fluid flow transport phenomena for rotating machinery and combustion and the development of turbulence model. Since 2003, he has been a professor of Department of Mechanical Engineering at Kumamoto University. His research interests are production and development of clean energy and renewable energy, thermal fluid flow transport phenomena using nanofluids, advanced cooling device development with the use of nanofluids and development of new clean fuel with the aid of shock-wave. 